\title{
Fixed Lingual Mandibular Growth Modificator: A new appliance for Class II correction
}

Osama Hasan Alali ${ }^{1}$

Introduction: This article demonstrates the description and use of a new appliance for Class II correction. Material and Methods: A case report of a 10-year 5 month-old girl who presented with a skeletally-based Class II division 1 malocclusion $\left(\mathrm{ANB}=6.5^{\circ}\right.$ ) on a slightly low-angle pattern, with ML-NSL angle of $30^{\circ}$ and ML-NL angle of $22.5^{\circ}$. Overjet was increased $(7 \mathrm{~mm})$ and associated with a deep bite. Results: Overjet and overbite reduction was undertaken with the new appliance, Fixed Lingual Mandibular Growth Modificator (FLMGM). Conclusion: FLMGM may be effective in stimulating the growth of the mandible and correcting skeletal Class II malocclusions. Clinicians can benefit from the unique clinical advantages that FLMGM provides, such as easy handling and full integration with bracketed appliance at any phase.

Keywords: Orthodontic appliance design. Functional orthodontic appliances. Angle Class II malocclusion.

Introdução: esse artigo apresenta, por meio de um relato de caso, a descrição e o uso de um novo aparelho (o Aparelho Lingual Fixo para Alteração do Crescimento Mandibular, ou Fixed Lingual Mandibular Growth Modificator, o FLMGM) para correção de má oclusão de Classe II. sendo a paciente do sexo feminino, de 10 anos e 5 meses de idade, com má oclusão esquelética de Classe II, divisão $1,\left(\mathrm{ANB}=6,5^{\circ}\right)$, com ângulos levemente baixos: ângulo SN.GoGn de $30^{\circ} \mathrm{e}$ ângulo PP.GoGn de $22,5^{\circ}$. A paciente apresentava sobressaliência aumentada $(7 \mathrm{~mm})$ associada a mordida profunda. Resultados: a sobressaliência e a sobremordida foram reduzidas com o novo aparelho descrito. Conclusão: o FLMGM pode ser efetivo na estimulação do crescimento da mandíbula e na correção da má oclusão esquelética de Classe II. O dentista clínico pode beneficiar-se das vantagens clínicas exclusivas do FLMGM, tais como a facilidade de manejo e a total integração com aparelhos com braquetes em qualquer fase do tratamento.

Palavras-chave: Desenho de aparelho ortodôntico. Aparelhos ortodônticos funcionais. Má oclusão de Angle Classe II.

${ }^{1}$ MDS in Orthodontics, Teaching Assistant, Graduate-PhD

Contact address: Osama Hasan Alali

P.O.box: 10256 - Aleppo, Syrian Arab Republic

E-mail: osama-alali@hotmail.com
How to cite this article: Alali OH. Fixed Lingual Mandibular Growth Modificator: A new appliance for Class II correction. Dental Press J Orthod. 2013 July-Aug;18(4):70-81.

Submitted: September 06, 2010 - Revised and accepted: June 20, 2011

" The patient displayed in this article previously approved the use of her facial and intraoral photographs.

" The authors report no commercial, proprietary or financial interest in the products or companies described in this article. 


\section{INTRODUCTION}

Many different appliances are now available for correcting skeletal Class II malocclusions. Some are removable ${ }^{1}$ such as activator and double-plate; and others are fixed ${ }^{2}$ such as Herbst appliance and MARA.

Double plate system, that was introduced for the first time by Schwarz in the early $1940 s,{ }^{3}$ is a reliable means for treating Angle Class II, Division 1 malocclusions ${ }^{4}$. Sander et al. ${ }^{5,6,7}$ have verified the effectiveness of this system in a number of studies, providing detailed information on the biomechanics and thus on the working principles. This effectiveness prompted the author to develop a fixed double-plate system, Fixed Lingual Mandibular Growth Modificator (FLMGM), that would not require patient compliance; especially because several studies ${ }^{8-11}$ have proven that fixed functional appliances are much more efficient in stimulating skeletal mandibular growth than removable ones.

From a clinical perspective, the FLMGM offers the following advantages:

1) Permanent effect, independent of patient compliance, as it is fixed.

2) Esthetics, as it is small and lingually located.

3) Eliminates the need for two separate treatment phases, as it is suitable for use in parallel with complete multibracket appliance in both arches.

4) Flexibility in treatment timing, as it can be used anytime during the mixed and permanent dentition.

5) No interference with occlusal development.

6) Wide and comfortable range of mastication movements, as the appliance consists of two separate parts with no permanent and physical intermaxillary connection.
7) Construction bite is unnecessary because of the easy and quick chairside reactivation and progressive advancement of the mandible in small increments.

8) Easy to handle because its insertion, clipping, and removal are very simple.

9) Economic and cost effective, because it does not involve ready-made components, and only one appliance is necessary for entire orthopedic phase.

\section{APPLIANCE DESIGN}

The FLMGM consists of two separate and fixed parts. The upper one is palatally positioned but bucally clipped to traditional upper molars bands (Fig 1A), while the lower is lingually welded to traditional lower molars bands (Fig 1B).

\section{Maxillary part}

It has the following components (Fig 2):

1) Acrylic button: it is similar to Nance button, and designed to connect wire elements of the maxillary part, preventing them from embedding into the mucosa. This button is seated on the anterior area of the palate as anterior as possible with no contact with front teeth (1-2 mm away from the gingival margin). Its dimensions should be as small as possible to allow mucosal and periodontal hygiene.

2) Two retention wires: one in each side, specifically designed by the author to give excellent retention, facilitate dealing with the appliance, and to enhance oral hygiene condition. They are fabricated with round $1 \mathrm{~mm}$ thick stainless steel orthodontic wire. The wires are anteriorly embedded into the acrylic button, run posteriorly without any contact with palatal mucosa, and each one contains an "U" loop with coil (giving some flexibility
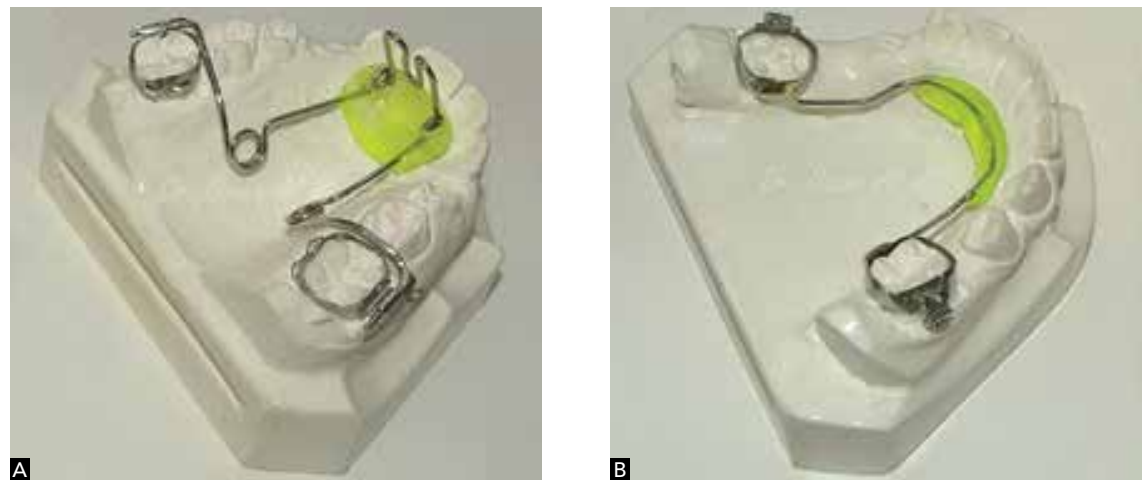

Figure 1 - Fixed lingual mandibular growth modificator (FLMGM). No physical attachment between maxillary (A) and mandibular (B) parts.

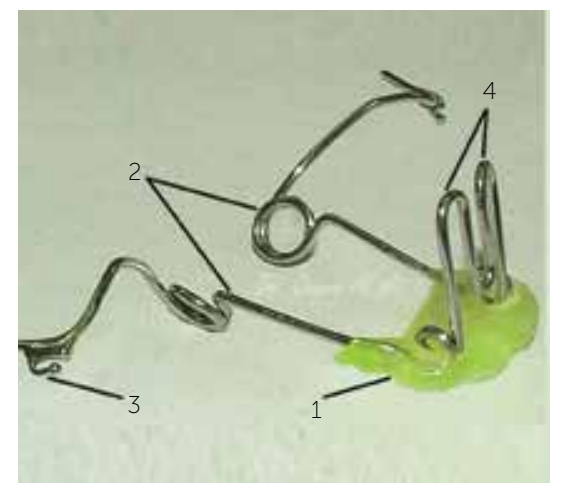

Figure 2 - Components of maxillary part: acrylic button (1); retention wires (2); retention hooks (3) and advancement loops (4). 
to help in easy insertion and removal) at the level of second upper premolar. After the coils, the wires should run perpendicular to the midline towards the vestibule at the level of the mesial surface of upper first molar through the interdental space. Then, in the vestibule, the wires should run posteriorly to enter into the headgear tube.

3) Two retention hooks: one in each side, have a ball end to avoid irritation, and are directed anteriorly and welded to the retention wire before entering the headgear tube.

4) Advancement loops: wire projection embedded in the acrylic button and extended towards the mandible. They consist of two consecutive long "U" loops, contain small protection coils where the wire exits the acrylic button, and are fabricated with round $1 \mathrm{~mm}$ thick hard stainless steel wire. The inclination of this advancing loops to the occlusal plane is about $70^{\circ}$, measured posteriorly. ${ }^{12}$

\section{Mandibular part}

It is made in a similar manner to a standard lingual arch with $1.0 \mathrm{~mm}$ stainless steel hard wire welded to the lingual aspect of first molars bands (Fig 3), and has the following features:

1) Its level in the anterior region must be $3-4 \mathrm{~mm}$ below the gingival margins of the incisors (Fig 4).

2) It includes an inclined guiding plane, made of acrylic resin, fixed on the anterior part of lingual arch, seated on the lingual alveolar mucosa below the level of incisors necks till the level of mouth floor, and it is smooth to allow sliding against the advancement loops during mandibular closing movement to reach its anterior position.

\section{CLINICAL PROCEDURE}

Separators are placed mesial and distal to the lower first molars. Subsequently, bands are selected and placed in position (Fig $5 \mathrm{~A}$ and C). Optionally, construction bite can be taken in an edge-to-edge mandible position. Upper and lower good alginate impressions are taken over the bands, with a good extension in the lingual sulcus. Bands are removed from the mouth and seated accurately in the impressions (Fig 5B and D). The impressions are sent to the laboratory for appliance fabrication. In the sequence, upper molar bands are cemented in position (Fig 6A). The inclined plane supported by lingual arch must be checked for stability, then the lower molar bands are cemented (Fig 6B). On the next day, maxillary part of corrector is attached to the upper molar bands (Fig 7A) by inserting the posterior ends of the retention wires into the headgear tubes. To ensure good stabilization of the maxillary part, an elastomeric ligature is used to tie the band hook and the retention hook together (Fig 7B).

\section{Reactivation visits}

Reactivation is generally required about every 2-3 months, and is carried out at the chairside, intra- or extraorally, by bending the advancement loops using orthodontic pliers.

\section{CASE REPORT}

\section{Diagnosis}

A 10-year 5-month-old girl presented with the chief complaints of the appearance of proclined upper incisors, retro-positioned chin, and dissatisfaction with her gingival smile. The family was concerned about the

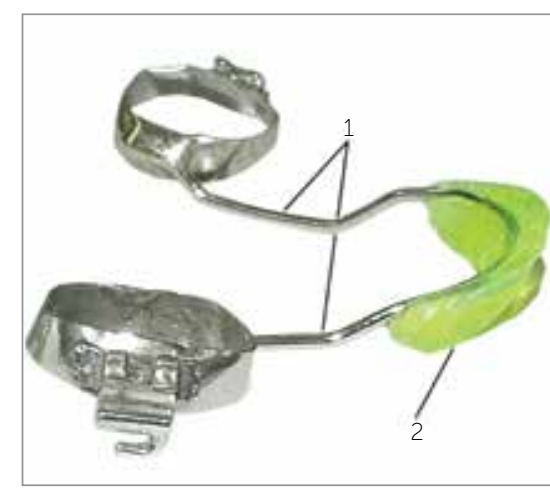

Figure 3 - Components of mandibular part: lingual arch (1) and inclined guiding plane (2)
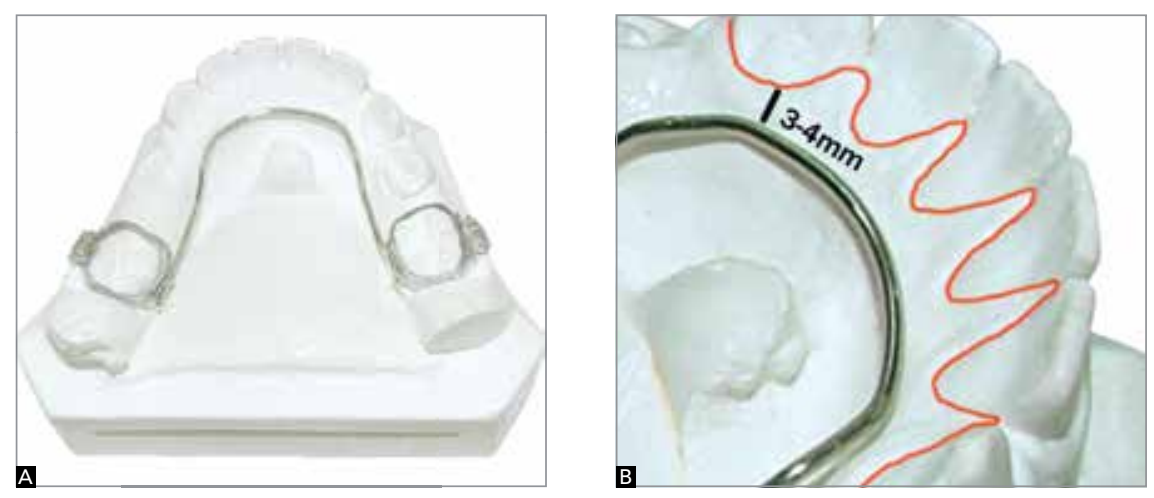

Figure 4 - Level of the lingual arch 3-4 mm below the gingival margin. 
lack of facial harmony and anxious for its improvement. The patient reported a history of bad oral habit, lower-lip sucking, many years ago and an early loss of four lower primary molars.

On examination, she presented with a Class II division 1 incisor relationship on a moderate Skeletal II bases. Clinical examination showed a convex-type facial profile with a decreased anterior lower facial height and obviously obtuse nasolabial angle (Fig 8A to C). Pretreatment intraoral examination of her dentition (Fig 8D to I) revealed that the pattern of oral hygiene was good and that she was in the late mixed dentition. The upper and lower labial segments were well aligned and slightly protrusive in appearance. There was some tipping of the lower right canine, first premolar and first permanent molar into the second primary molar extraction site. Apart from this slight constriction in the lower right buccal segment, the lower arch had a good form. In occlusion, the incisor relationship was Class II division I with an increased overjet of $7 \mathrm{~mm}$ and a traumatic deep bite of $5 \mathrm{~mm}$ (Fig $8 \mathrm{E}$ and $\mathrm{H}$ ). The upper dental midline was coincident with the facial midline, whilst the lower centerline was displaced $1 \mathrm{~mm}$ to the right. The molar relationship was an end-on (half unit) Class II on the left side and Class I on the right (Fig $8 \mathrm{G}$ and $\mathrm{I}$ ).
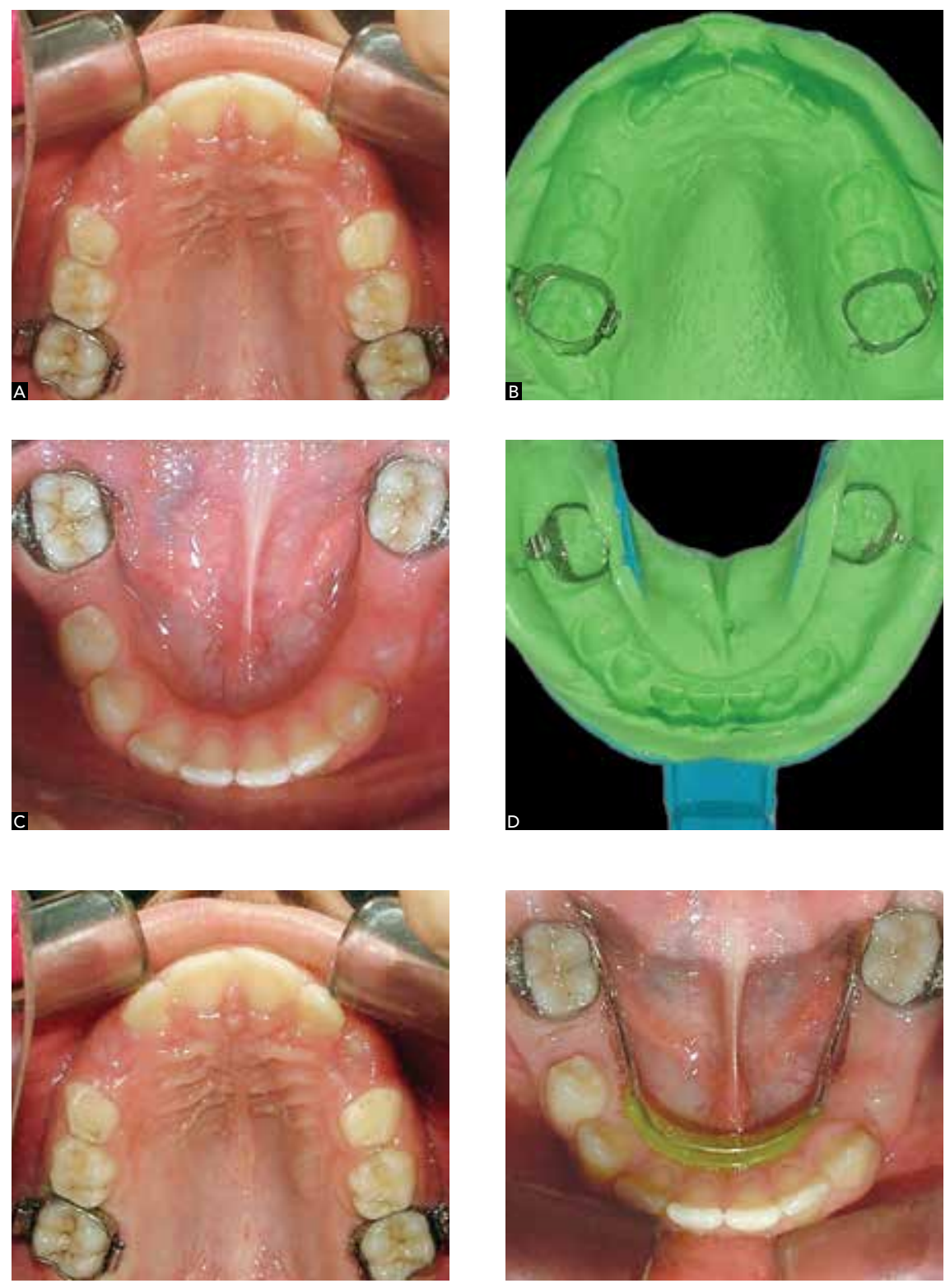

Figure 5 - Molar bands placed in situ (A and C) and repositioned in alginate impressions ( $B$ and $\mathbf{D}$ )

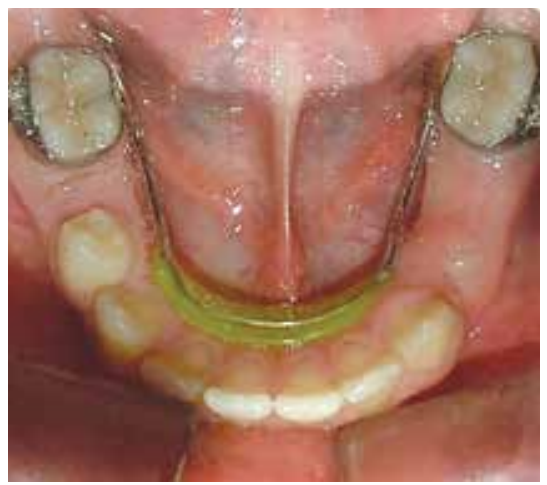

Figure 6 - The upper bands and the mandibular part cemented in place. 

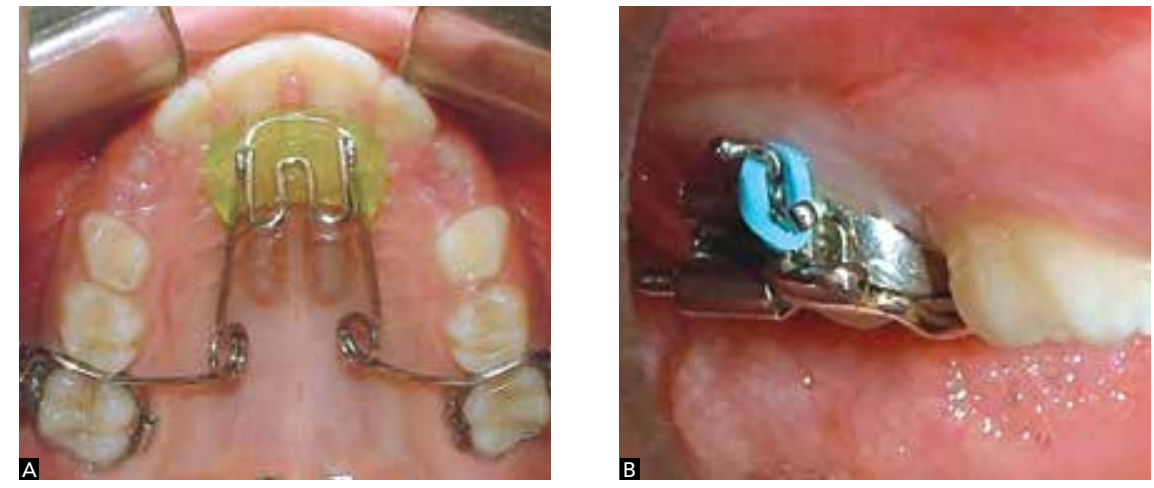

Figure 7 - Maxillary part inserted into headgear tubes (A) and an elastomeric ligature placed between the band hook and the retention hook to clip the maxillary part (B).
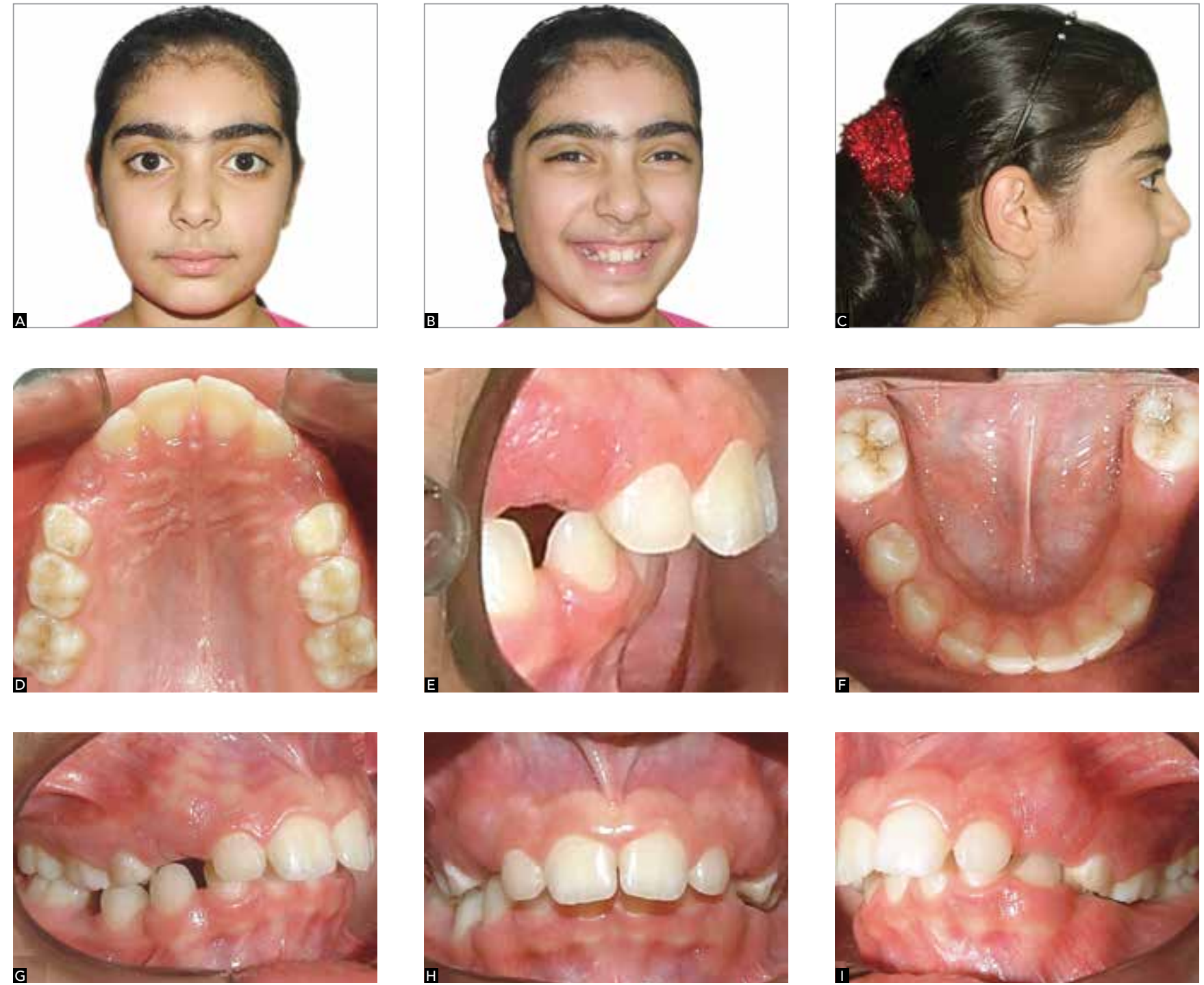

Figure 8 - Pretreatment facial and intraoral photographs (age 10 years and 5 months). Increased overjet and overbite. 

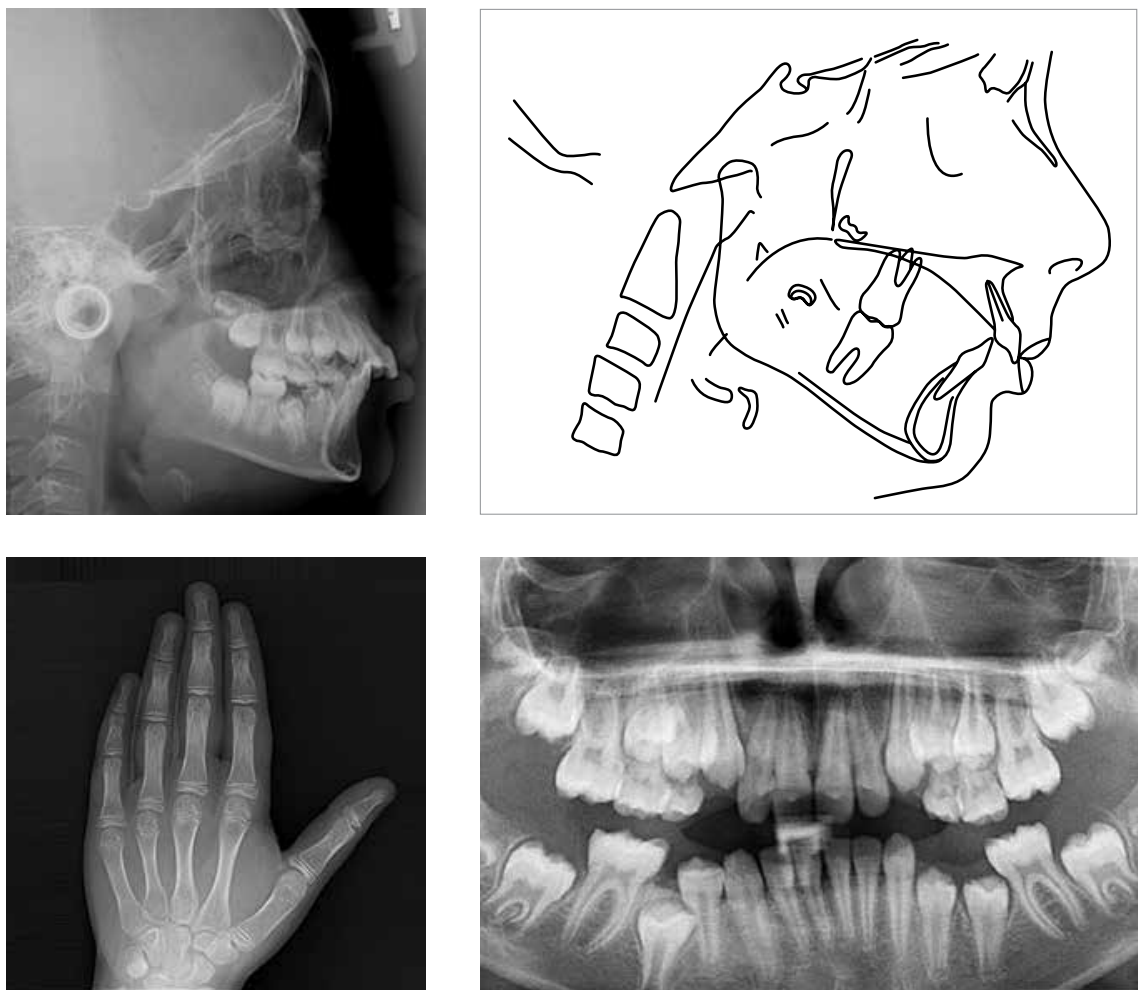

Figure 9 - Pretreatment radiographs and cephalometric tracing.
Cast analysis revealed arch-length discrepancies of $+3 \mathrm{~mm}$ and $-3 \mathrm{~mm}$ in the upper and lower arches, respectively. The lower right first molar was mesially drifted. The lateral cephalometric radiograph analysis (Fig 9 and Table 1) confirmed that, skeletally, the patient had a moderate Class II jaw relationship, ANB was $6.5^{\circ}$, and a reduced maxillomandibular plane angle, the MLNL was $22.5^{\circ}$. Dentally, there was a degree of bimaxillary proclination and the interincisal angle was $120.5^{\circ}$. Soft tissue profile showed that the upper lip was slightly behind ' $E$ ' line, and the nasolabial angle was obviously obtuse $\left(124^{\circ}\right)$.

Assessment of hand-wrist radiograph (Fig 9) indicated considerable skeletal growth potential remaining. The patient was in the MP3cap stage.

Panoramic radiograph (Fig 9) revealed no obvious pathology present. The lower right second premolar was impacted. In addition, the third molars were developing.

\section{Treatment objectives}

The objectives of nonextraction treatment for the patient were identified as follows: (1) Reduce the anteroposterior skeletal disharmony; (2) Establish ideal overjet and overbite relationship; and (3) Achieve a functional occlusion with good interdigitation.
Table 1 - Cephalometric summary

\begin{tabular}{lccc}
\hline \multicolumn{1}{c}{ variables } & $\mathrm{T}_{0}$ & $\mathrm{~T}_{1}$ & $\Delta\left(\mathrm{T}_{1}-\mathrm{T}_{0}\right)$ \\
\hline SNA (degrees) & 84 & 83 & -1 \\
\hline SNB (degrees) & 77.5 & 80 & +2.5 \\
\hline ANB (degrees) & 6.5 & 3 & -3.5 \\
\hline NSAr (degrees) & 128.5 & 126 & -1.5 \\
\hline SNL.NL (degrees) & 7.5 & 7 & -0.5 \\
\hline SNL.ML (degrees) & 30 & 31 & +1 \\
\hline NL.ML (degrees) & 22.5 & 24 & +1.5 \\
\hline U1.SNL (degrees) & 108 & 104.5 & -3.5 \\
\hline U1.NL (degrees) & 116 & 111.5 & -4.5 \\
\hline L1.ML (degrees) & 101.5 & 98.5 & -3 \\
\hline Interincisal angle (degrees) & 120.5 & 126 & +5.5 \\
\hline Upper lip (mm) & -1 & -2 & -1 \\
\hline Lower lip (mm) & 1 & 1 & 0 \\
\hline Nasolabial angle (degrees) & 124 & 127.5 & +3.5 \\
\hline
\end{tabular}

$\mathrm{T}_{0}$ : Pre-treatment records (Fig 9),

$\mathrm{T}_{1}$ : after 8 months and 1 week of orthopedic correction (Fig 13).

\section{Treatment plan}

Two-phase nonextraction approach was planned. For the first phase (orthopedic), treatment goal was to stimulate mandibular growth, improving facial appear- 
ance and profile, and reduce the overjet and overbite to an acceptable level (with re-evaluation after 8 months). During the second phase (orthodontic), the goal would be to maintain the improvement achieved in the orthopedic phase, and to obtain a functional occlusion with a Class I molar and canine relationships. Retainers would be placed immediately after appliances were removed for retention purposes.

\section{Treatment progress}

At 10 years and 5 months, FLMGM was used to improve skeletal Class II by stimulating mandibular growth.
The patient was very motivated with the treatment. An additional motivating factor is the noticeable improvement of facial appearance when FLMGM is fitted. The patient was instructed to bite in an edge-toedge position and to keep her lips in touch as much as possible (Fig 11). The patient was seen regularly at 6 weeks intervals, and at each visit, the occlusion was checked. The lip seal was maintained throughout treatment. At 11 years and 3 months, to assess the orthopedic changes, only the maxillary part was removed, and a set of facial and intraoral photographs was taken (Fig 12); and radiographs were requested (Fig 13).

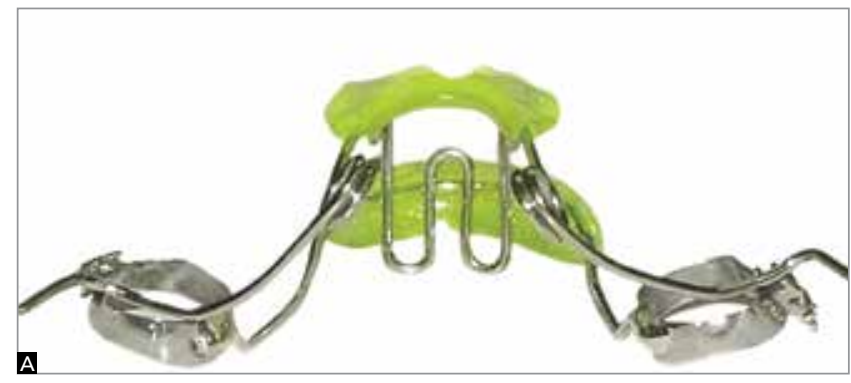

Figure 10 - Design of FLMGM: Posterior (A) and lateral (B) views.

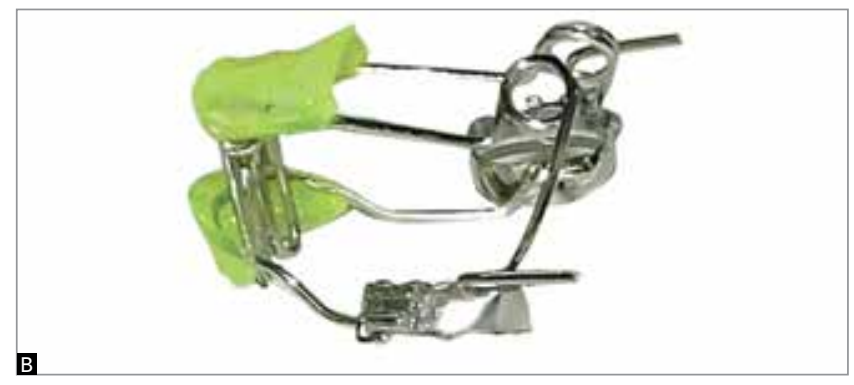

B 


\section{Results achieved}

Through the course of FLMGM correction, about 8 months, the overjet was reduced from $7 \mathrm{~mm}$ to approximately $2 \mathrm{~mm}$, normal incisor and canine relationships were established, vertical eruption of lateral segments was enhanced, the lower midline coincided with the soft tissue midline, and a nice improvement in the facial esthetics and balance were achieved (Fig 12).

Data derived from cephalometric analysis (Fig 13 and Table 1) and superimpositions (Fig 14) reveal that there was continued vertical growth with valuable change in the anteroposterior relationship. Skeletally, ANB an- gle decreased from $6.5^{\circ}$ to $3^{\circ}$, indicating that FLMGM caused skeletal change. Anteroposterior growth of the maxilla was held, although A point still came forward. SNB angle increased by $2.5^{\circ}$, and significant growth of the mandible occurred. ML-NSL angle increased by $1^{\circ}$. Dentally, even with no brackets, the tipped-out upper incisors underwent $4.5^{\circ}$ of uprighting, and the lower incisors were extruded and slightly uprighted by $3^{\circ}$, which is considered quite surprising. Eventually, interincisal angle increased to a good value, $130^{\circ}$. In addition to vertical movement, the maxillary first molars also moved distally (Headgear effect) as shown in Figure 14.
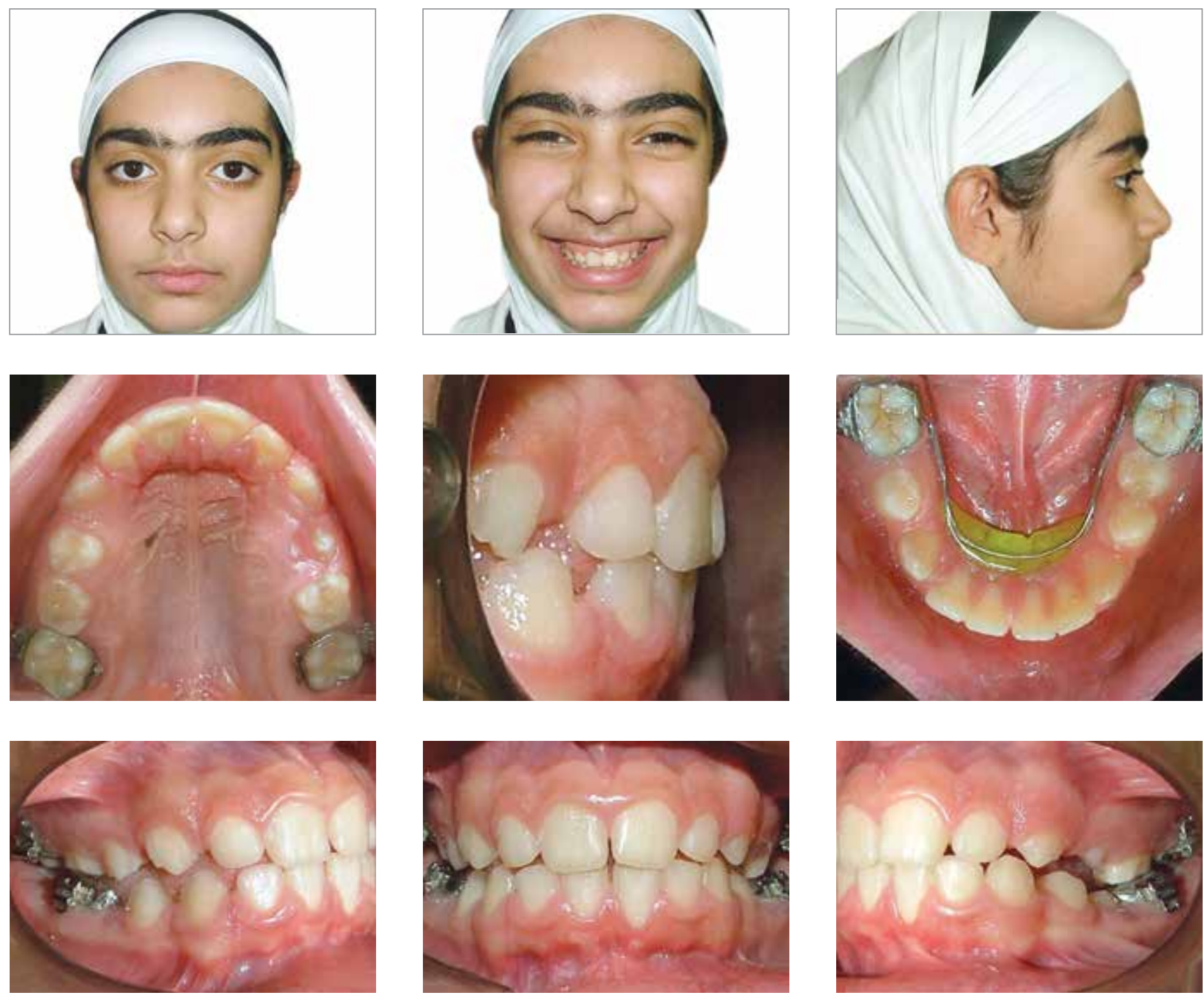

Figure 12 - Facial and intraoral photographs immediately after removal of the maxillary part, promoting a normal incisor relationship, with buccal segments partially out of occlusion. 

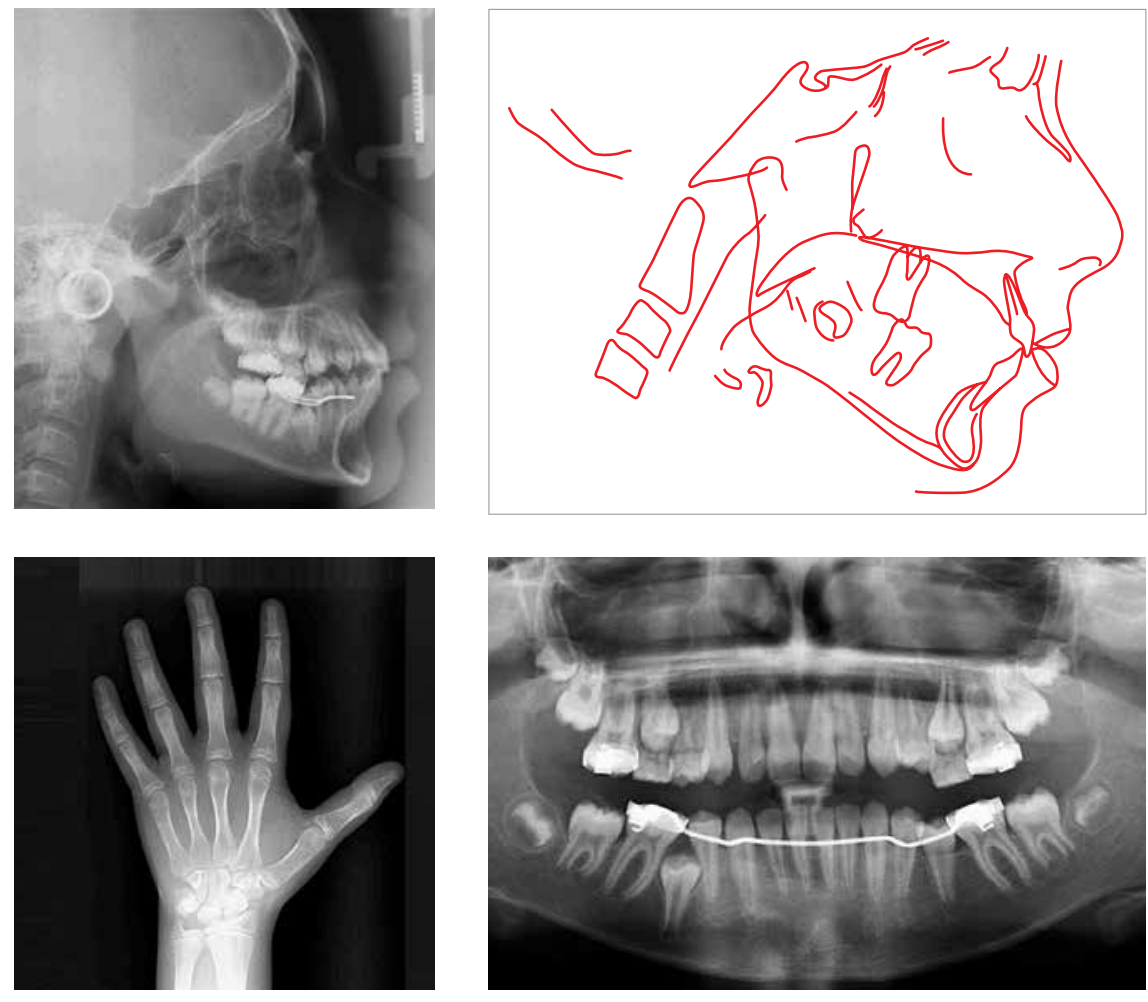

Figure 13 - Radiographs and cephalometric tracing after orthopedic treatment.
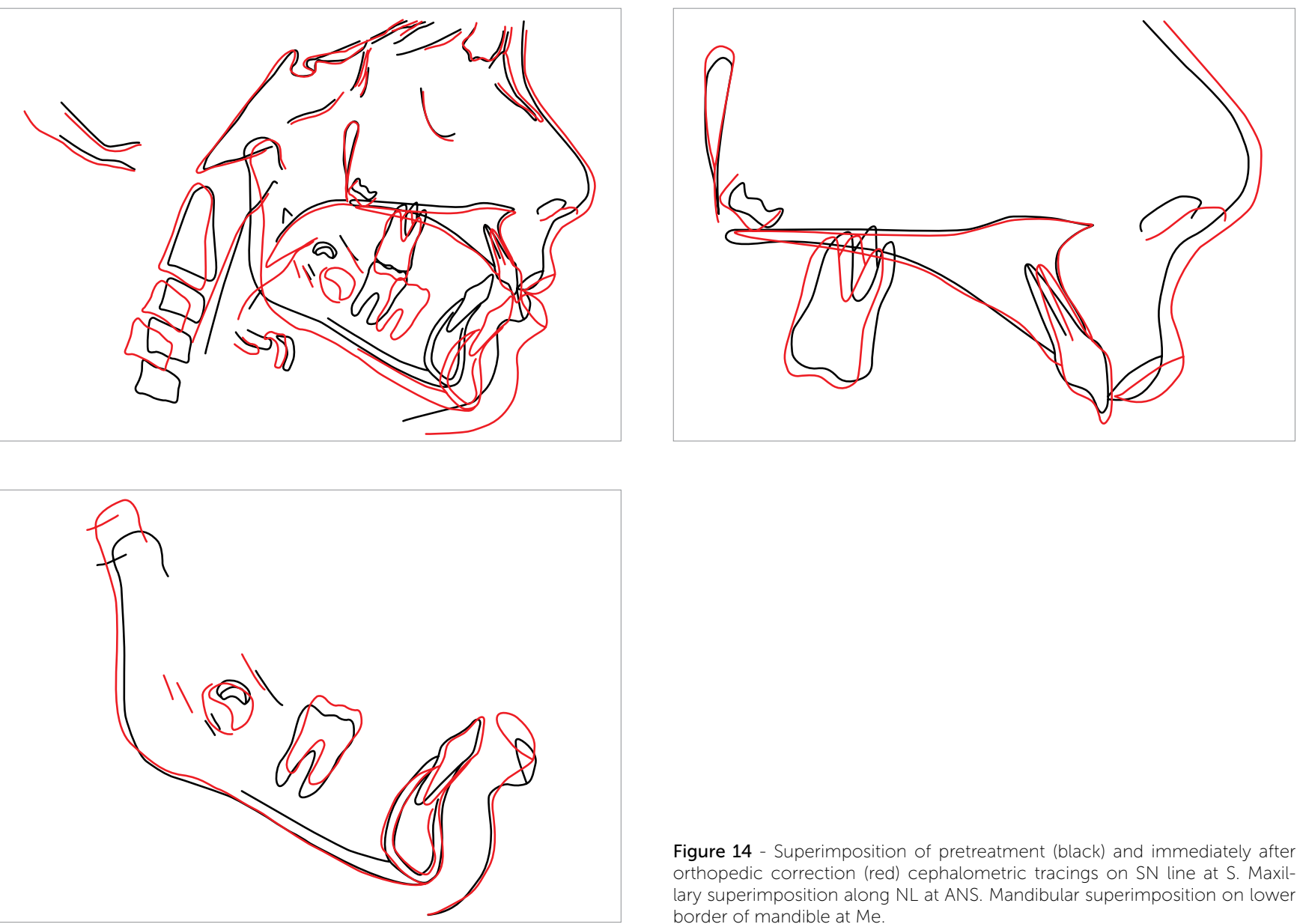

Figure 14 - Superimposition of pretreatment (black) and immediately after orthopedic correction (red) cephalometric tracings on SN line at S. Maxillary superimposition along NL at ANS. Mandibular superimposition on lower border of mandible at Me. 


\section{DISCUSSION}

In a growing patient, better aesthetic result would ideally be obtained by using orthopedic appliances to accelerate mandible development. ${ }^{13-17}$ The FLMGM has effectively been used by the author in skeletal Class II division 1 patients, and a $\mathrm{PhD}$ clinical research is now in progress to identify its effectiveness. In the present case, the author attempted to stimulate mandible growth using FLMGM that was well tolerated without complications. Within 8 months of orthopedic treatment, the overjet was considerably enhanced, and the facial harmony was good. The uprighting of incisors was favorable, and this is believed to be resulting from the mechanism of breaking balance between the tongue and lips. While the vertical loops work as a shield relieving the tongue pressure on the incisors, only lingually-directed functional forces generated by the sealed lips affect the incisors and cause lingual crowns tipping.

Conceptually, FLMGM represents an exercise device for the facial and masticatory muscles, in the same way as other functional appliances. It is proven that muscular training is important factor in the normal development of bone. ${ }^{18}$ After the appliance is placed, the patient is asked to keep his mouth closed as long as possible. Once the patient closes his mouth, the inclined plane and the advancement loops will come in contact in the anterior area of the mouth. By continuation of mouth closing, the inclined plane will be forced to slide against the loops, and eventually the mandible will take a predetermined forced anterior position (Fig 15). Functional force, generated by muscles that attempt to return the mandible posteriorly to its original position, ${ }^{19}$ causes the upper acrylic button and the lower acrylic inclined plane to apply pressure on the oral mucosa, and this in turn is supposed to cause proprioceptive response that repositions the mandible forward in the same way as the Fränkel II Regulator ${ }^{20}$. In the first period, the patient avoids collision between the loops and the inclined plane by forward-mandibular movement, and with time, the mandible functions without interference in the desired position and the patient will automatically, via neuromuscular reprogramming, close comfortably into the protrusive position. The repetition of the new closure pattern results in orofacial musculature reeducation and induces skeletal adaptation. ${ }^{19}$
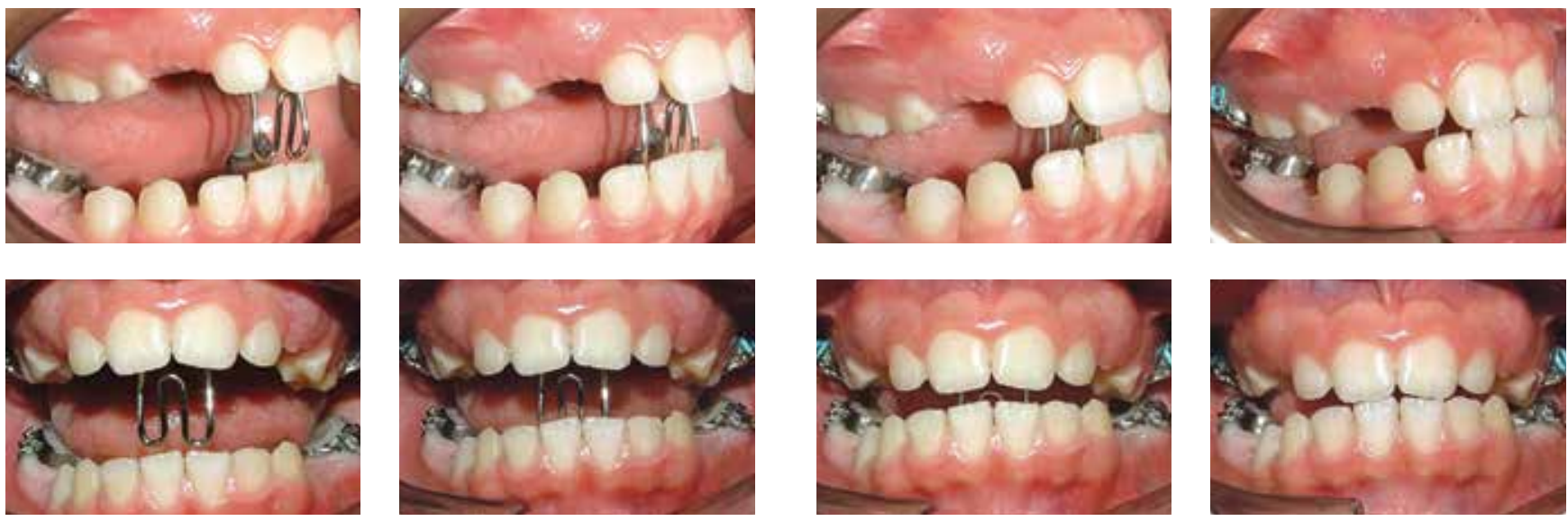

Figure 15 - Mode of action.
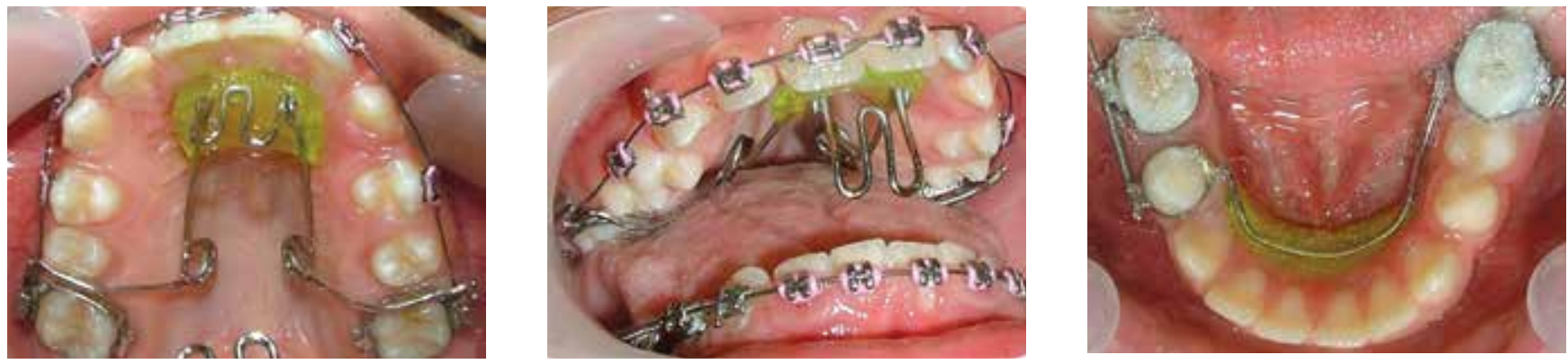

Figure 16 - Coordination of FLMGM with full-bonded appliance. 

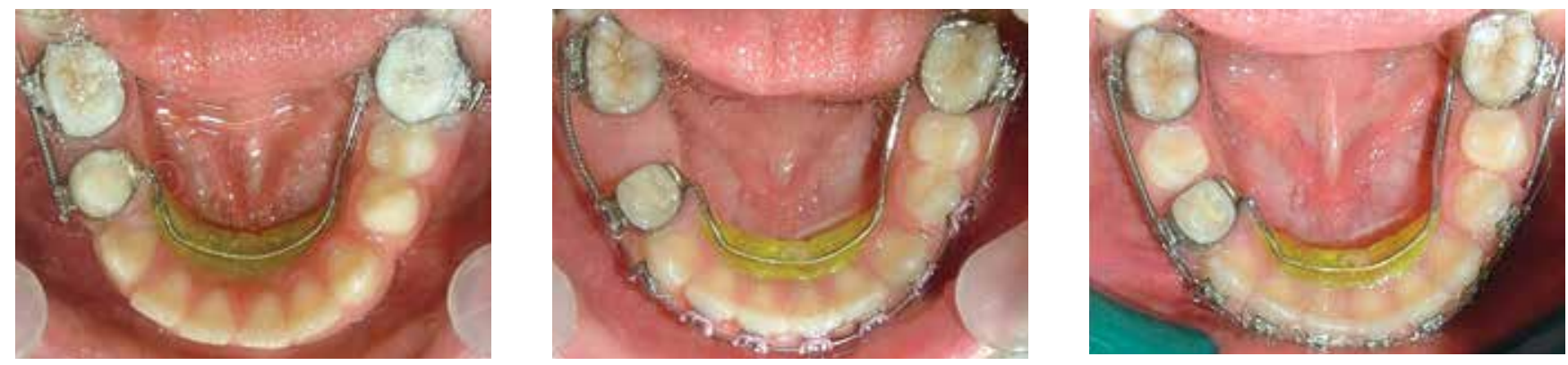

Figure 17 - Mandibular part was modified, and an open coil spring was used to deliver distal force required to distalize the lower right molar. After that, lower right second premolar spontaneously erupted.

Technically, the FLMGM represents a fixed version of the removable double-plate appliance because the two appliances follow an identical mechanism of action, based on incorporating an inclined plane in the mandible and guide bars in the maxilla. The most important two advantages of FLMGM over removable double-plate are: (1) FLMGM is active full-time, regardless of patient cooperation; (2) With FLMGM, the functional appliance phase is not separated from but completely integrated with the bracketed appliance phase (Fig 16). In clinical practices, although not many orthopaedic appliances are suitable for this integration, Dynamax and MARA do approach it. ${ }^{11,21}$

When FLMGM alone in place during orthopaedic or retention phases, fully or partially bracketed appliances can be bonded. Another alternative is to integrate the FLMGM with an existing bracketed appliance. This coordination is a significant feature allowing maximum skeletal Class II correction without extending treatment time and delaying the progress of treatment by eliminating a major drawback of many orthopedic appliances, where there is often a need for an additional interim stabilizing phase, to avoid the relapse which may be seen if the orthopedic phase is abruptly discontinued. Leveling and aligning the dentition and erupting the buccal segment to achieve good interdigitation using fixed appliances, while the FLMGM is maintaining mandibular advancement, is a crucial factor in stability of skeletal correction outcomes.

\section{Extra advantages}

- The vertical growth of the alveolus is enhanced during the FLMGM treatment phase, this may be ascribed to two reasons: (1) the upper and lower teeth are free because the FLMGM is supported only by the permanent molars; (2) When the mandible is in a protruded position, there is adequate interocclusal space available for spontaneous eruption.

- The need for permanent extractions may be reduced during mixed dentition FLMGM treatment because the lingual arch maintains the leeway space, and in some cases, it can be modified to help in molar distalization (Fig 17).

- In case of still-active thumb-sucking habit, advancement loops effectively can block the thumb from making contact with the palate.

- In cases associated with lower lip sucking, a lip bumper may be buccally added to the mandibular part of corrector to modify the soft tissue as well.

\section{Disadvantages}

- The patient may complain of irritation from the vertically extended advancement loops.

- Swallowing, eating and speaking could be cumbersome, in contrast with buccally positioned appliance, yet the patient accepts it and gets used to it soon.

- Oral hygiene is somewhat difficult in the lower lingual anterior area, but has not been a problem.

\section{CONCLUSIONS}

The FLMGM appliance is economic, can be used starting from the mixed dentition and may be effective in stimulating the growth of the mandible and correcting skeletal Class II malocclusions associated with bimaxillary dentoalveolar protrusion. Clinicians can benefit from the unique clinical advantages the FLMGM provides, such as easy handling and full integration with bracketed appliance at any phase. 


\section{REFERENCES}

1. Bishara S. Functional appliances: a review. Am J Orthod Dentofacial Orthop. 1989;95(3):250-8.

2. McSherry PF, Bradley $\mathrm{H}$. Class II correction-reducing patient compliance a review of the available techniques. J Orthod. 2000:27(3):219-25

3. Altuna G, Schumacher HA. Schmuth and Muller Double Plates. J Clin Orthod. 1985;19(6):422-5

4. Lisson JA, Tränkmann J. Effects of Angle Class II, Division 1 treatment with Jumping-the-Bite appliances: a longitudinal study. J Orofac Orthop. 2002:63(1):14-25

5. Sander FG. Indikation für die Anwendung der Vorschubdoppelplatte. Prakt Kieferorthop. 1988:2:209-22.

6. Sander FG. Der Nachteffekt bei der Anwendung der Vorschubdoppelplatte. Prakt Kieferorthop. 1989:3:97-106

7. Sander FG, Lassak C. Die Beeinflussung des Wachstums mit der Vorschubdoppelplatte im Vergleich zu anderen funktionskieferorthopädischen Geräten. Fortschr Kieferorthop. 1990:51:155-64.

8. Cozza P, Baccetti T, Franchi L, De Toffol L, McNamara JA Jr Mandibular changes produced by functional appliances in Class II malocclusion: a systematic review. Am J Orthod Dentofacial Orthop 2006:129(5):599.e1-12; discussion e1-6.

9. McNamara JA Jr, Howe RP, Dischinger TG. A comparison of the Herbst and Fränkel appliances in the treatment of Class II malocclusion. Am J Orthod Dentofacial Orthop. 1990:98(2):134-44

10. Nelson C, Harkness M, Herbison P. Mandibular changes during functional appliance treatment. Am J Orthod Dentofacial Orthop. 1993;104(2):153-61.
11. Pangrazio-Kulbersh $\mathrm{V}$, Berger JL, Chermak DS, Kaczynski R, Simon ES, Haerian A. Treatment effects of the mandibular anterior repositioning appliance on patients with Class II malocclusion. Am J Orthod Dentofacial Orthop. 2003:123(3):286-95

12. Kinzinger G, Ostheimer J, Förster F, Kwant PB, Reul H, Diedrich P. Development of a new fixed functional appliance for treatment of skeletal Class II malocclusion: first report. J Orofac Orthop. 2002; 63(5):384-99.

13. Fränkel R. Decrowding during eruption under the screening influence of vestibular shields. Am J Orthod. 1974;65(4):372-406.

14. Graber TM, Rakosi T, Petrovic A. Dentofacial orthopedics with functional appliances. St. Louis: C.V. Mosby; 1997.

15. Bass NM. Orthopedic coordination of dento-facial development in skeletal class II malocclusion in conjunction with edgewise therapy. Part I. Am J Orthod. 1983:84(6):466-90.

16. Clark WJ. Twin block functional therapy: applications in dentofacial orthopaedics. London: Mosby-Wolf; 1995

17. Pancherz $\mathrm{H}$. The Herbst appliance: its biological effects and clinical use. Am J Orthod. 1985:87(1):1-20

18. Fränkel R. Concerning recent articles on Fränkel appliance therapy. Am J Orthod. 1984:85(5):441-7.

19. Graber TM, Neuman B. Removable orthodontic appliances. Philadelphia WB Saunders; 1984

20. McNamara JA. On the Fränkel appliance. Part I. Biological basis and appliance design. J Clin Orthod. 1982;16:320-37

21. Bass NM. The Dynamax System: a new orthopaedic appliance and case report. J Orthod. 2006:33(2):78-89. 